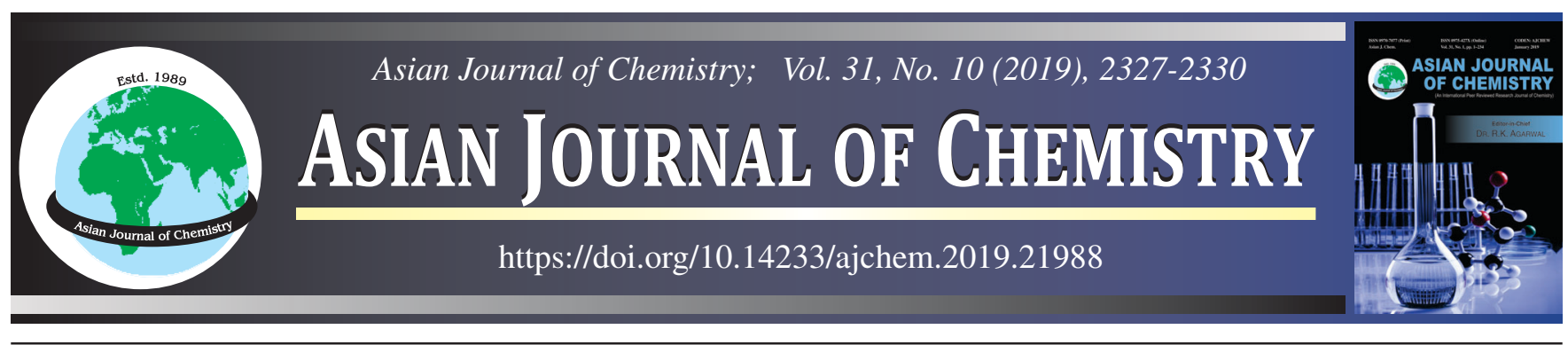

\title{
Effect of Doped Indium Tin Oxide on Bonding and Morphology of Monomer Cholesteryl Acrylate
}

\author{
Afrizal $^{1, *}$, Arif Rahman ${ }^{1}$, Nurul Hidayati ${ }^{1}$ and S. IwAN ${ }^{2, *}$
}

${ }^{1}$ Department of Chemistry, Universitas Negeri Jakarta, Rawamangun, Jakarta, Indonesia

${ }^{2}$ Department of Physics, Universitas Negeri Jakarta, Rawamangun, Jakarta, Indonesia

*Corresponding author: E-mail: afrizal@unj.ac,id

Received: 8 February 2019;

Accepted: 9 June 2019;

Published online: 30 August 2019;

AJC-19545

Monomer cholesteryl acrylate was doped by indium tin oxide (ITO) which succeeded in becoming composites in photopolymerization process using UV curing method having various polymerization time $(15,20,25,30$ and $35 \mathrm{~min})$ at $60-70{ }^{\circ} \mathrm{C}$. The goal of this study is to know the effect of polymerization time to characterize the conductivity properties of composite cholesteryl acrylate-ITO. All the spectra confirmed the peaks at $600-550 \mathrm{~cm}^{-1}$ which attributed the doping of ITO in the composite cholesteryl acrylate-ITO. The XRD patterns of polymer cholesteryl acrylate-ITO has nematic chiral phase at $2 \theta=15-20^{\circ}$. Some of the peaks are appeared at $15.2734^{\circ}$ and $16.7266^{\circ}$, while other peaks of indium tin oxide appeared at $30^{\circ}, 50^{\circ}$ and $60^{\circ}$. The surface morphology of polymer cholesteryl acrylate-ITO showed the existence of sphere. The value conductivity of polymer cholesteryl acrylate-ITO is found to be $1.8390 \times 10^{-10} \mathrm{~S} / \mathrm{m}$.

Keywords: Cholesteryl acrylate, Indium tin oxide, Photopolymerization.

\section{INTRODUCTION}

Process of photopolymerization is one of the polymerization techniques that use electromagnetic radiation beam as an initiator in the process of monomer initiation. This technique is called UV curing technique. One of the factors that affect process UV curing is ability of the radiation beam to be used. The source of radiation source is UV lamp. Cholesteryl acrylates have acrylate functional group that can be polymerized. Process of polymerizations monomer cholesteryl acrylate for making polymer cholesteryl acrylate. According to literature [1] polymer cholesteryl acrylate can be use for applications. To have maximal at application, in this study cholesteryl acrylate was doped by material conductor is indium tin oxide (ITO). Therefore, doped ITO could be increasing conductive properties of polymer cholesteryl acrylate.

The cholesteryl acrylate molecules are arranged as thin films and parallel to each other forming a helix continuously and regularly. Each layer in the cholesterol structure has a rigid parallel molecular direction on the top and bottom layers. Layers with the direction or orientation of the molecule will be repeated and have a high degree of stability. The spaced molecular value of the twisted acrylates of acrylates is expressed by the pitch value $(\mathrm{P})$ by undergoing a full $360^{\circ}$. The pitch value of the resulting crystalline cholesteryl acrylate will be the base when applied. Its value is strongly influenced by the temperature and addition of other substances (dopants) mixed with the cholesteryl acrylate. Substances added in this study are indium tin oxide (ITO) in which conductive oxide materials have transparent properties [1-3]. According to the literature successfully perform the photopolymerization of perfluorinated acrylic compounds using UV radiation with a wavelength range of 350-450 $\mathrm{nm}$ and heated using hotplate at a temperature of $160{ }^{\circ} \mathrm{C}$ for $1 \mathrm{~h} \mathrm{[4]}$.

Addition of ITO into monomer cholesteryl acrylat while was polymerized can be a material can be using for many applications. ITO can be changed structures of monomer cholesteryl acrylate, especially that monomomer cholesteryl acrylate was polymerized. Therefore, this paper reports the influence of ITO doped on bonding and morphology of monomer cholesteryl acrylate. For polimerizations process did variations of time polymerization on photopolymerizations are: $15,20,25,30$

This is an open access journal, and articles are distributed under the terms of the Attribution 4.0 International (CC BY 4.0) License. This license lets others distribute, remix, tweak, and build upon your work, even commercially, as long as they credit the author for the original creation. You must give appropriate credit, provide a link to the license, and indicate if changes were made. 
and $35 \mathrm{~min}$. In addition, this work analyzed how the effect of ITO dopant on the value of the conductivity of the resulting cholesteryl acrylate-ITO polymer [4].

\section{EXPERIMENTAL}

Materials used in this study include acrylic precursor synthesis, cholesterol, DMAP, DCC and ITO. The materials used for the synthesis of acrylic precursors are EHB, CBA, $\mathrm{K}_{2} \mathrm{CO}_{3}, \mathrm{KI}, \mathrm{KOH}, \mathrm{HCl}$, acrylate acid, hydroquinone and PTSA. Instruments for product analysis include Fourier transform infrared (FTIR), LCR-meter, scanning electron microscopy (SEM), energy dispersive X-ray (EDX), X-ray diffraction (XRD).

Synthesis of cholesteryl acrylate: A total of $2.00 \mathrm{~g}$ of acrylic precursor, acryloyloxy butyloxy benzoate (ABB), treated with $200 \mathrm{~mL}$ of dichloromethane solvent and $1.72 \mathrm{~g}$ of DCC, were then incorporated in a three round neck flask connected to a Liebig cooler. Previously, it was first conditioned to start with the stirrer at 0-5 rpm; $\mathrm{C}$, then after pour in a rounded and mixed base flask, then distilled for $30 \mathrm{~min}$ at $0-5 \mathrm{rpm}$; $\mathrm{C}$ and flowed with $\mathrm{N}_{2}$ gas. Then the added mixture of cholesterol as much as $3.00 \mathrm{~g}$ and DMAP as much as $0.2 \mathrm{~g}$ and then distirrer back for $5 \mathrm{~h}$ at room temperature. After that the filtered product and the formed filtrate are evaporated to form a brown precipitate. The adduct is added methanol and heated until dissolved. The resulting mixture is cooled in the refrigerator to form crystals and filtered. The resulting precipitate and filtrate are then purified by column chromatography using hexane:ethyl acetate $=5: 1$. The product formed is recrystallized with methanol solvent. Photopolymerization of composite cholesteryl acrylate-ITO at variations of time polymerization $[5,6]$. Sample preparations are made according to the five variations of time polymerizations. Each preparations sample consisted of $20 \mathrm{mg}$ of monomer cholesteryl acrylate-ITO dissolved using a pure grade dichloromethane solvent in a small beaker. Then the solution was added $1 \mathrm{~mL}$ initiator of darocure 1173. Added dopant ITO much as $20 \%$ and then the solution is oriented on the plate glass plate. Then the glass plate preparation is inserted into the UV-curing tool. The heating temperature at the hotplate is set at a temperature range of $60-70{ }^{\circ} \mathrm{C}$. Polymerization process with time polymerization are 15, 20, 25, 30 and $35 \mathrm{~min}$. The result of this process is a thin film material which will then be characterized.

\section{RESULTS AND DISCUSSION}

Monomer cholesteryl acrylate was added by ITO in process of photopolymerization. In generally that process known as the addition polymerization through the following steps: initiation, propagation and termination. The first step initiation is the formation of a cholesteryl acrylate radical of monomer. Propagation step is propagating of chain of polymer. The termination step is stop propagate of chain of polymer. All the step going the radiations process that sample of monomer cholesteryl acrylate and ITO was irradiated with lamp UV.

Process of photopolymerizations was performed at variations time of radiations, different polymerization time are 15,20 , 25,30 and $35 \mathrm{~min}$ that temperature process at $60-70{ }^{\circ} \mathrm{C}$. The photopolymerization process using $10 \mathrm{mg}$ of a monomer of cholesteryl acrylate was dissolved in a pure grade dichloro- methane solvent and then added an initiator of Darocore 1173 $1 \mu \mathrm{L}$ and $20 \%$ added dopan ITO the mixture was placed to a 2 $\mathrm{mm} \times 2 \mathrm{~mm}$ glass plate. Used Darocure 1173 as the initiator for working on ultraviolet light absorption areas with wavelengths between 225 to $375 \mathrm{~nm}$ this corresponds to the work of photoinitiators on photopolymerization using UV Curing method.

Analysis function group of polymer cholesteryl acrylateITO using spectrum FTIR (Fig. 1) showed bonding between cholesteryl with ITO. Based on spectrum product polymer in process time length radiation of $15 \mathrm{~min}$ until $35 \mathrm{~min}$ the peak shifting to bigger wavenumber. This phenomenon maybe because bonding between atomic carbon with oxygen more strength in molecule polymer cholesteryl acrylate-ITO. The peak in wavenumber of $1707.00-1701.21 \mathrm{~cm}^{-1}$ for vibration interaction between In-OH bond with C-O bond. This is because the interaction of the cholesteryl acrylate polymer with ITO surface. Based on the above IR absorption spectra analysis spectra that of the four samples the polymer cholesteryl acrylateITO contains two overlapping peaks in the $3398.57 \mathrm{~cm}^{-1}$ wavelength bands until $3334.92 \mathrm{~cm}^{-1}$ which is thought to be the vibration of the $\mathrm{O}-\mathrm{H}$ bonds of the alcohol and carboxylates, it is assumed that the $\mathrm{O}-\mathrm{H}$ peak of the alcohol originates from the initiator of Darocure 1173.

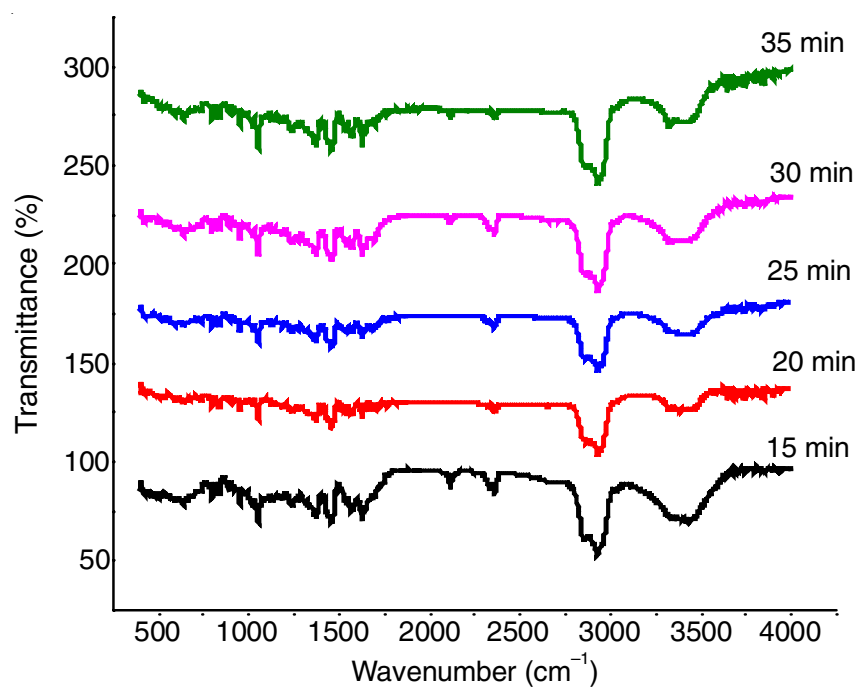

Fig. 1. FTIR spectrum of polymer cholesteryl acrylate-ITO from UV curing that resulted at $15,20,25,30,35$ min time of polymerizations

There are some overlap peaks in wavenumber 1051.34 $\mathrm{cm}^{-1}$, this is showed vibration C-O with peak for vibration In$\mathrm{OH}$ in ChoA-ITO in spectrum polymer was resulted at $15 \mathrm{~min}$. Other overlap in ChoA-ITO in spectrum polymer was resulted at $20 \mathrm{~min}$ in wavenumber $1051.94 \mathrm{~cm}^{-1}$. And other in ChoA-ITO in spectrum polymer was resulted at $25 \mathrm{~min}$ in wavenumber $1053.51 \mathrm{~cm}^{-1}$; in ChoA-ITO was resulted at $30 \mathrm{~min}$ in wavenumber $1054.71 \mathrm{~cm}^{-1}$; in ChoA-ITO was resulted at 35 min in wavenumber $1057.11 \mathrm{~cm}^{-1}$. That wavenumber which is assumed to be vibration of $\mathrm{C}=\mathrm{O}$ carbonyl bond, according to Afrizal (2010) there is peak at $1729 \mathrm{~cm}^{-1}$ region which is carbonyl group. Then at the wavenumber $1550 \mathrm{~cm}^{-1}$ until 1690 $\mathrm{cm}^{-1}$ that predict is the presence of aromatic $\mathrm{C}=\mathrm{C}$ bonds $[7,8]$.

Characterizations of polymer cholesteryl acrylate-ITO by $\mathrm{X}$-ray diffraction pattern can be seen in Fig. 2. In this paper 


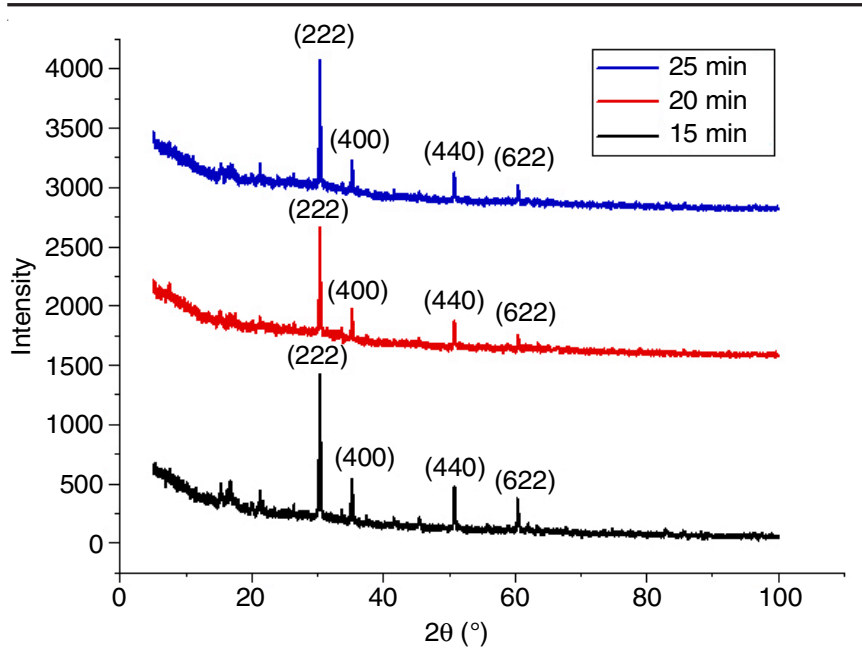

Fig. 2. Diffractogram of polymer cholesteryl acrylate-ITO from UV curing using lamp 25 watt and 40 watt

reported XRD that polymer was resulted at time polymerizations 15, 20 and $25 \mathrm{~min}$. Based on difractogram that polymer cholesteryl acryalate has phase nematic chiral at peak $2 \theta=$ $15-20^{\circ}$. Some peaks appeared are $15.2734^{\circ}$ and $16.7266^{\circ}$. Polymer cholesteryl acrylate-ITO was resulted at time polymerizations 20 min shows peaks appeared are $15.2267^{\circ}$ and $16.7352^{\circ}$. Polymer that was resulted in time polymerizations $25 \mathrm{~min}$ shows peaks appeared are $15.2771^{\circ}$ and $16.7256^{\circ}$.

Other peaks for identifications of ITO $2 \theta$ at $30^{\circ}, 50^{\circ}$ and $60^{\circ}$. Peaks at $2 \theta$ starting at $30^{\circ}$ which is stated to be the peak of ITO crystallinity. Based on the top reference the characteristics of ITO are $2 \theta=30^{\circ}$ which has a crystal (222) oriented area of Bodycentered cubic (bcc) [9]. High intensity at peak XRD assumed any interaction between cholesteryl acrylate with ITO it is proven on IR data appear peak at wavenumber region is about at $1700 \mathrm{~cm}^{-1}$ which is a carbonyl group is thought to emerge a new peak because the $\mathrm{C}=\mathrm{O}$ bond interacts with $\mathrm{In}_{2} \mathrm{O}_{3}$. The growth of ITO changes the intensity of the new structures formed at which the ITO peaks appear small and if the amount is less, then the crystallinity of polymer is also formed. The existence of ITO can change the crystal field orientation of the polymer cholesteryl acrylate-ITO, so the smaller ITO percentage is given the more crystalline peaks formed in the polymer, this is reinforced by Xu et al. [10] that the liquid crystal can be doped by a conductive oxide with a smaller percentage so that the crystalline peak of the liquid crystal is formed.

Fig. 3 show that the photo-SEM of polymer cholesteryl acrylate-ITO that existence of spheres on the surface of morphology, then the picture A shows the surface morphology in the sample which looks not yet fully mixed between the polymer and ITO seen the significant micrograph difference the form of bars and spheres in which ITO has a distinctive sphereshaped morphology. Based on the reference [11-13] that the polymer cholesteryl acrylate has a bar shape with fibers that branch off and morphological structures form a crosslinked network or crosslinks after polymerization. SEM image of B and $\mathrm{C}$ the agglomerate has begun to appear on the surface between composite of polymer cholesteryl acrylate-ITO with the marked cross-linked tissue. It has been succeeded that the ITO material can be used as filler or filler or dopant on a polymer matrix i.e. cholesteryl acrylate polymer. Furthermore, in the photo $\mathrm{D}$ the surface morphology looks to be stacked together, presumably the pile is between the polymer cholesteryl acrylateITO and byproducts. EDAX results shows composition of
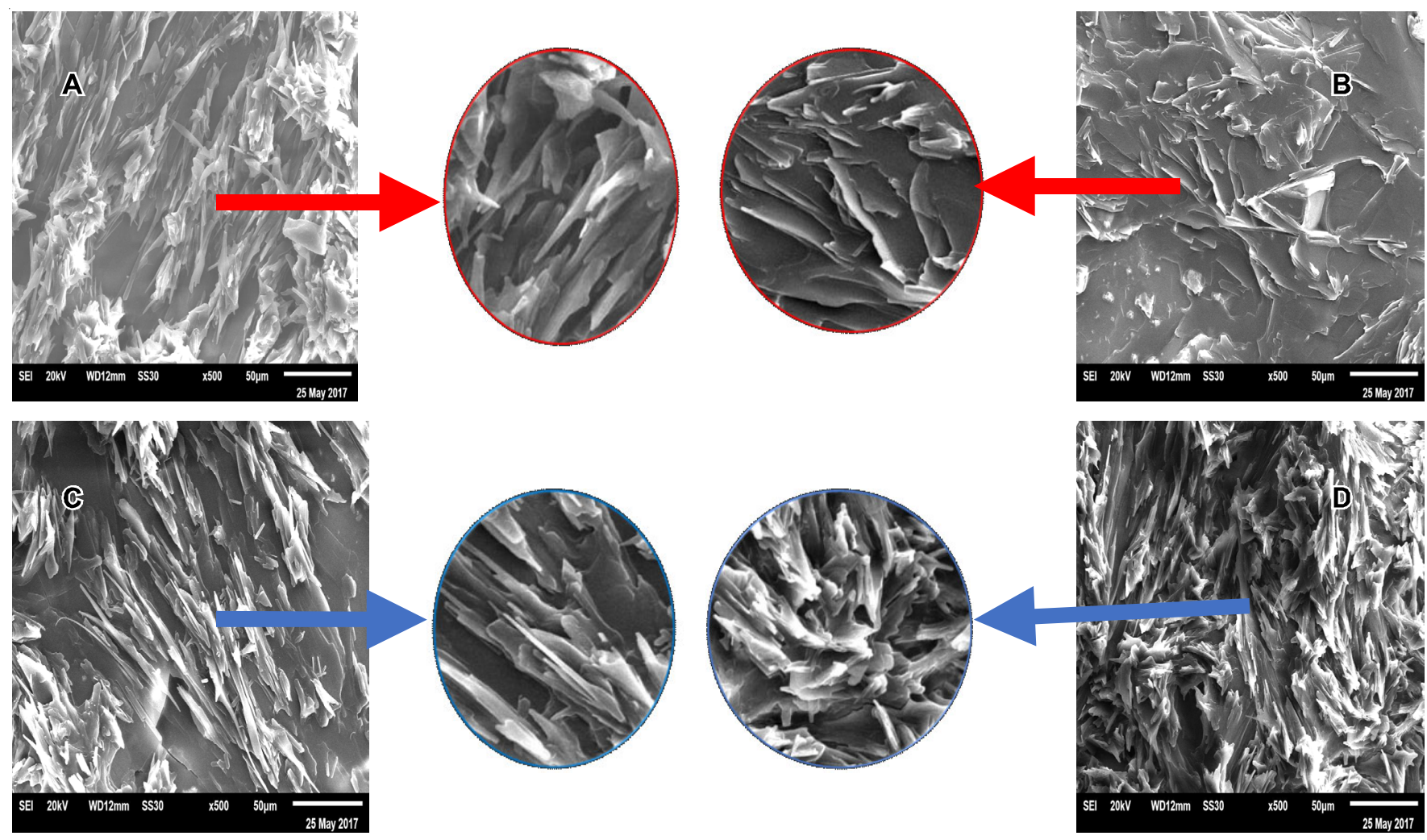

Fig. 3. SEM of polymer cholesteryl acrylate-ITO 
polymer cholesteryl acrylate are carbon with mass amount $95.84 \%$, oxygen equal to $2.90 \%$ while indium equal to $0.55 \%$ $[14,15]$.

Test of conductivity polymer cholesteryl acrylate-ITO showed that polymer was resulted in time polymerizations $20 \mathrm{~min}$ highest conductivity value is $1.8390 \times 10^{-10} \mathrm{~S} / \mathrm{m}$. This phenomenon showed that $20 \mathrm{~min}$ time polymerizations is greater the energy absorbed by monomer cholesteryl acrylate in initiation process. Time photopolymerizations that longer result more than radical of monomer cholesteryl acrylate formation. Therefore, many process propagations happened between monomer with other molecule monomer cholesteryl acrylate. But in time polymerizations for 30 and 35 min showed that conductivity value a significant decrease. This is happen because the radical is formed faster so that the polymerization process more quickly occurs, the short-formed polymer chain [16,17].

\section{Conclusion}

Indium tin oxide (ITO) had influenced monomer cholesteryl acrylate by process UV curing founded polymer cholesteryl acrylate-ITO. UV curing method with variations of time polymerizations showed characterization different polymer of cholesteryl acrylate-ITO. Polymer cholesteryl acrylate-ITO was resulted by time polymerizations at 20 min that characterization by SEM have been agglomerated on morphological surface and there are elements of PKA-ITO i.e. carbon $95.84 \%$, oxygen $2.90 \%$ and indium $0.55 \%$ and it's conductivity value 1.8390 $\times 10^{-10} \mathrm{~S} / \mathrm{m}$.

\section{ACKNOWLEDGEMENTS}

This research was supported by Program Hibah Penelitian Dasar from Kementrian Riset Teknologi dan Pendidikan Tinggi Republik Indonesia, LPPM UNJ Nomor: 8/SP2H/DRPM/ LPPM-UNJ/II/2018 and Nomor : 5/SP2H/DRPM/LPPM-UNJ/ III/2019.

\section{CONFLICT OF INTEREST}

The authors declare that there is no conflict of interests regarding the publication of this article.

\section{REFERENCES}

1. I. Imae, Y. Nakamura, K. Komaguchi, Y. Ooyama, J. Ohshita and Y. Harima, Sci. Technol. Adv. Mater, 13, 045005 (2012); https://doi.org/10.1088/1468-6996/13/4/045005.

2. D. Pedrazzoli, A. Dorigato, T. Conti, L. Vanzetti, M. Bersani and A. Pegoretti, Express Polym. Lett., 9, 709 (2015); https://doi.org/10.3144/expresspolymlett.2015.66.

3. S. Lai, Y. Wu, J. Wang, W. Wu and W. Gu, Optical Mater. Exp., 8, 1585 (2018); https://doi.org/10.1364/OME.8.001585.

4. C.Y. Ho, F.H. Lin, Y.T. Tao and J.Y. Lee, Sci. Technol. Adv. Mater, 12, 065002 (2011); https://doi.org/10.1088/1468-6996/12/6/065002.

5. J.W. Park, G.S. Shim, J.G. Lee, S.W. Jang, H.J. Kim and J.N. Choi, Materials, 11, 509 (2018);

https://doi.org/10.3390/ma11040509.

6. F. Liu, Y. Wang, X. Xue and H. Yang, Polymer (Korea), 40, 390 (2016); https://doi.org/10.7317/pk.2016.40.3.390.

7. S.A. Mani, S.U. Hadkar, P.J. Jessy, S. Lal, P. Keller, S. Khosla, N. Sood and P. Sarawade, J. Inf. Disp., 17, 169 (2016); https://doi.org/10.1080/15980316.2016.1241832.

8. Q. An, Z. Ei, P. In, Z. Heng, M. Ingrui, Z. Uang and W. Lin, Optical Mater. Exp., 8, 228 (2018); https://doi.org/10.1364/OME.8.001536

9. K. Ali, S.A. Khan and M.Z.M. Jafri, Nanoscale Res. Lett., 9, 175 (2014); https://doi.org/10.1186/1556-276X-9-175.

10. H. Xu, O. Trushkevych, N. Collings and W.A. Crossland, Mol. Cryst. Liq. Cryst., 502, 235 (2009); https://doi.org/10.1080/15421400902817346.

11. R.-Y. Yang, C.-J. Chu, Y.-M. Peng and H.-J. Chueng, Adv. Mater. Sci. Eng., 2012, Article ID 741561 (2012); https://doi.org/10.1155/2012/741561.

12. N.-W. Pu, W.-S. Liu, H.-M. Cheng, H.-C. Hu, W.-T. Hsieh, H.-W. Yu and S.-C. Liang, Materials, 8, 6471 (2015); https://doi.org/10.3390/ma8095316.

13. C. Hengst, S. Menzel, G. Rane, V. Smirnov, K. Wilken, B. Leszczynska, D. Fischer and N. Prager, Materials, 10, 245 (2017); https://doi.org/10.3390/ma10030245.

14. D. Choi, S.J. Hong and Y. Son, Materials, 7, 7662 (2014); https://doi.org/10.3390/ma7127662.

15. A. Abderrahmen, F.F. Romdhane, H.B. Ouada and A. Gharbi, Sci. Technol. Adv. Mater., 9, 025001 (2008); https://doi.org/10.1088/1468-6996/9/2/025001.

16. M. Al-Tweissi, I.O. Ayish, Y. Al-Ramadin, A.M. Zihlif, Z.M. Elimat and R.S. Al-Faleh, J. Nano- Electron. Phys., 10, 02006 (2018).

17. H. Chen, M. Hu, F. Peng, J. Li, Z. An and S.-T. Wu, Opt. Mater. Express, 5, 655 (2015); https://doi.org/10.1364/OME.5.000655. 